\title{
Using Research on Homework to Improve Remote and Hybrid Learning
}

Jeremy Roschelle and Nicola M. Hodkowski December 2020

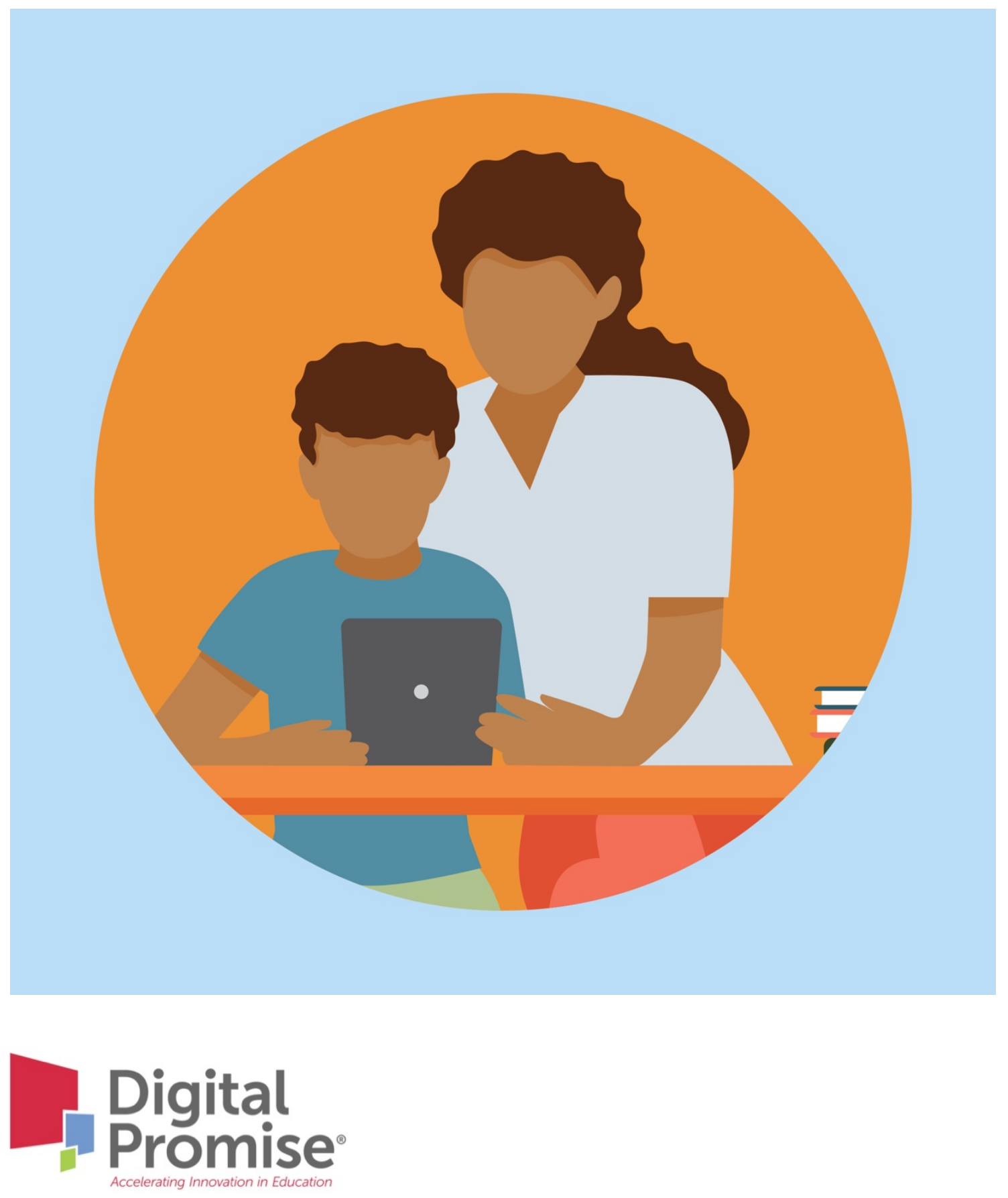




\section{Suggested Citation}

Roschelle, J. \& Hodkowski, N.M. (2020). Using research on homework to improve remote and hybrid learning [White Paper]. San Mateo, CA: Digital Promise.

http://hdl.handle.net/20.500.12265/107

\section{Acknowledgements}

Thank you to Mingyu Feng, WestEd, for comments on a draft and her support. This material is partially supported by the Institute of Educational Sciences (IES) of the U.S. Department of Education under Grant Number R305A170641. Any opinions, findings, and conclusions or recommendations expressed in this material are those of the authors and do not necessarily reflect the views of IES.

\section{Contact Information}

Email: jroschelle@ digitalpromise.org and nhodkowski@digitalpromise.org

Digital Promise:

Washington, DC:

1001 Connecticut Avenue NW, Suite 935

Washington, DC 20036

San Mateo, CA:

2955 Campus Dr. Suite 110

San Mateo, CA 94403

Website: https://digitalpromise.org/

(C)(0) BY NC SA
This work is licensed under a Creative Commons Attribution NonCommercial 4.0 International License. 


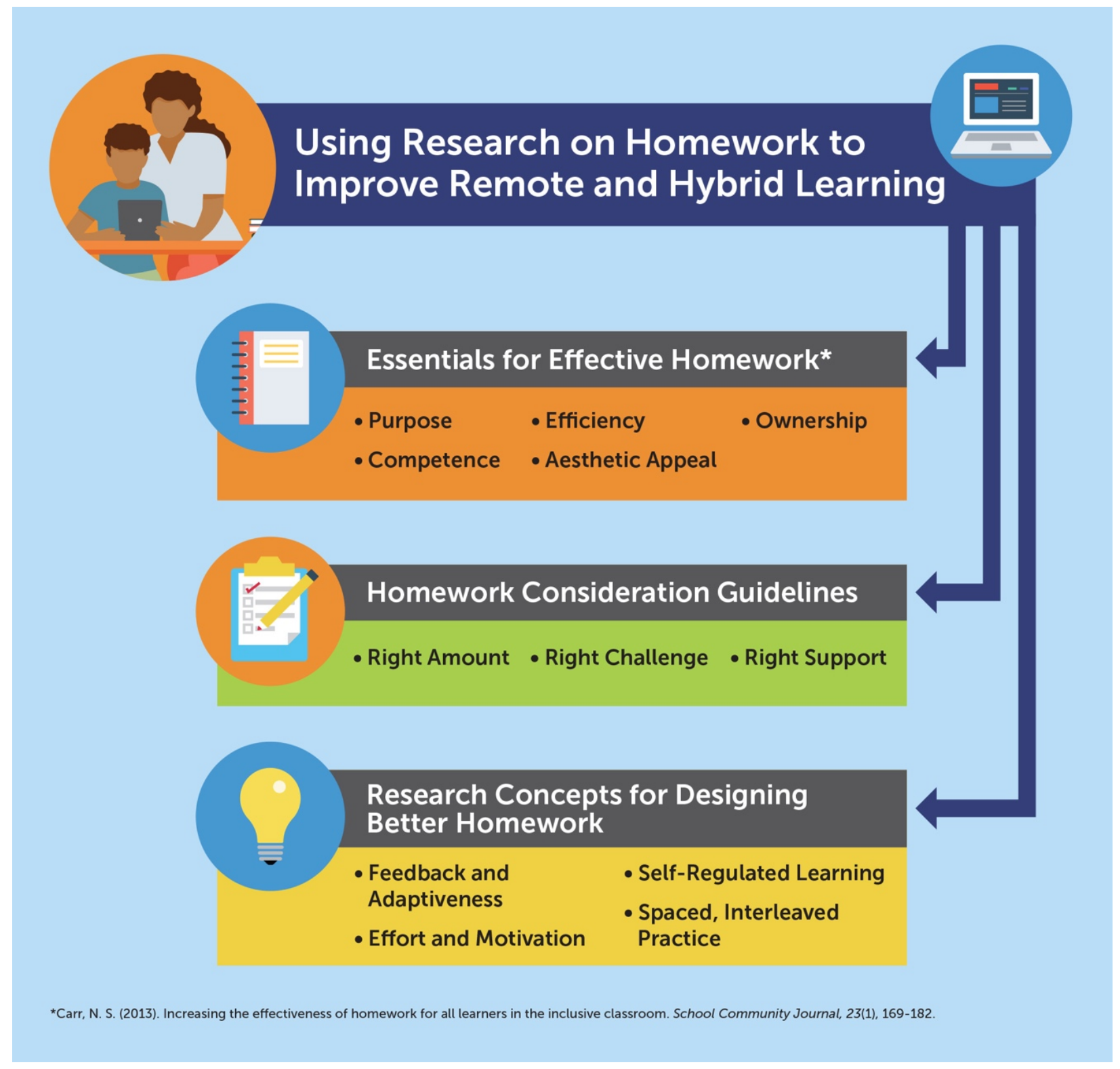

Due to the COVID-19 pandemic, many students are learning remotely or in a hybrid of remote and in-school learning. As a result, most teachers and students are in learning situations where more independent work is assigned to students. There is no research that directly speaks to this unprecedented situation. There is, however, a considerable body of established research to draw on about assigning independent work to students to do at home: research on homework. Further, technology to support homework is becoming more available and research supports its effectiveness. In this article, we review some of the major points of this established research and suggest how schools, teachers, and parents and guardians can apply this research and related technology now, during the pandemic. 


\section{What is Homework?}

Homework is a task assigned to students by teachers that is meant to be carried out during non-instructional time (Cooper et al., 2012), without direct teacher involvement. Homework research shows that most homework has favorable impacts on student learning (Carr, 2013; Cooper et al., 2012; Dettmers et al., 2010).

We begin with a caution: homework is a "non-instructional" tool. This means that homework research will not explain how to provide primary instruction in new concepts to students via hybrid or remote learning, nor will it inform us about how teachers should interact with students during a video conference call. On the other side, remote and hybrid instruction means students are being asked to do more homework-like assignments (e.g., asking students to work independently on assignments). Now is the time to figure out how to make independent assignments better.

\section{Five Essentials for Effective Homework}

Research has found that effective homework has five fundamental qualities (Carr, 2013):

1. Purpose: Homework should be meaningful for learning; it should not be "busy work."

2. Efficiency: Homework should be short and sweet. Students should feel they are using their time and effort well.

3. Ownership: Students should own how and when they do homework (as appropriate to their age) and see it as something they are doing for their own learning.

4. Competence: Students must believe they can succeed at an assignment; conversely, giving students homework that they don't believe they can complete, or quickly get stuck while doing, is counter-productive.

5. Aesthetic Appeal: Homework should be uncluttered and visually appealing.

For teachers who are pressed for time, we suggest starting by getting the purpose right. Clear and concise directions are important to helping students in the necessary understanding of why the assignment will help them learn, such as:

- "I am making notes so I can participate in tomorrow's discussion."

- "I am practicing a skill to check my own mastery and to know what to ask for more help on."

- "I am exploring a science simulation to come up with some 'I wonder' questions for the project meeting tomorrow."

Research shows that when homework has the purpose of preparing for the next day's lesson, students benefit more than when homework is just about spending extra time on same-day content (Cooper et al., 2012). Now is the time to stop using homework as a meaningless ritual ("because that's the way it's always been") or to meet someone else's expectations ("our 
school expects I'll assign homework."). Homework should purposely connect to some larger arc of learning. If you stop reading this article here, this is the message we hope you take away:

\section{Homework is effective when it's part of a larger story about how people learn-a story} that both teachers and students believe in and collaborate to achieve.

\section{The Right Amount, Right Challenge, and Right Supports}

Research tells us that homework improves learning when students receive the right amount of homework, with the appropriate level of challenge and appropriate supports.

Although results do not all line up perfectly, research tends to find that homework is more effective for high school and middle school students than elementary students (Carr, 2013; Cooper et al., 2012). This is likely because one's ability to learn independently increases with age. A common guideline is that the total amount of homework across all subjects should be 10 minutes per night per grade level. This means a maximum of 30 minutes of independent learning time is suitable for a third grader, but 120 minutes (or two hours) is feasible for a high school student. Since more learning and practicing of learning is happening at home, the 10 minute per night may need to be adjusted slightly. Teachers only have limited synchronized instruction time in remote learning environments. Thus, students are required to spend more time working asynchronously. This may mean the 10 minutes per night is increased to also include some time that may have once been considered as school selfstudy time.

However, there is some caution regarding too much of an increase in independent work. For lower grades, teachers must be careful not to assume that time formerly blocked as "desk work time" in a classroom can now be directly transitioned to homework, or that they can fill up an "at-home school day" with homework. The guideline amount of time still generally applies because most commonplace homework assignments aren't essential to learning; with much more limited time available, it's best to focus only on those homework assignments that have the strongest learning purpose.

To be effective, homework should also be at the right level of challenge. It has to be easy enough that students can do it, but hard enough that they have to apply mental effort. One reason to limit the amount of time for homework is so that students can put some real effort into it. Individualized homework assignments (especially those assigned per specific learning needs) outperform non-individualized ones in terms of improving student achievement, attitudes, and conduct (Cooper et al., 2012). So it is important to think about the student's interests, abilities, and needs, and hence, what would make sense for that student to work on independently. For those who teach many classes and many students, this may mean offering a homework choice board for students to choose from. Another option is for teachers to differentiate homework based on the three main areas of practice they notice are needed for the majority of the students they teach. 
Research also finds that resources for doing homework are not equitably available to all students. For example, avital resource to consider may be a quiet, well-lit space to do homework. Homework settings may vary from household to household. It is important to think about students' lives outside of school and what homework can be assigned that students can gain from given their particular settings and situations. Another possible source of inequity is if homework requires a computer and a broadband connection. A recent report from the National Center for Education Statistics surveyed teachers about student access to computers for homework and found that although a computer and internet may exist in a student's home, that does not necessarily mean the computer is available for use for homework or that the internet is reliable to complete online homework (Gray \& Lewis, 2020).

Thus, teachers need to ask about the resources that students have at home so they can design assignments that are equitable. In other words, assignments can be completed taking into account the various resources students do and do not have available to them. For students who are struggling or are in special education programs, support will need to go beyond differentiation to providing additional resources.

\section{Four Ideas for Designing Better Homework}

We hope that by sharing the below ideas from scientifically established learning theory, teachers can develop sound ideas to use now and in the future for designing homework to improve students' learning.

\section{(1) Feed back and adaptiveness make homework better.}

Research clearly shows that when students receive timely feedback on homework, they learn more (Elawar \& Corno, 1985). Conversely, when students get little or very delayed feedback on how well they are doing, homework can't possibly help them to learn because they might be practicing errors.

When computers are available, they can help by giving students immediate feedback on their work, as well as useful hints (Mendicino et al., 2009). In a rigorous study (Roschelle et al., 2016), we found that using computer-collected information can also help teachers to adapt, and helps students to learn much more. A computer platform called ASSISTments gave students immediate feedback on math homework as they were doing it. The platform also helped teachers by scoring and reporting students' math homework. Teachers could easily see which of the homework problems were challenging for most students and therefore spend more instructional time on the "harder" problems. They could also see common wrong answers and help students reflect on their answers.

When computers aren't available, consider whether students (or older siblings or parents) can help. Providing some students with the even problems and the odd answer key, and their teammates with the opposite, invites students to give each other feedback. Being adaptive to students' homework experiences improves the quality of teaching. Students learn more. What does this mean now? For the limited amount of high-quality homework they will 
assign, teachers should make sure they've thought about how to hold students accountable for work in order to give timely feedback and how they will adapt their instruction based on the patterns they notice.

\section{(2) Self-regulated learning is the ability for a student to plan, monitor, reflect on, and adjust their own learning.}

Becoming a self-regulating learner is an important outcome. Being self-regulated means that students will be able to direct their own ongoing learning and succeed at it, even after school hours and graduating from school altogether. Consider this for a moment: Schools will not be able to cover the same amount of subject matter content during the pandemic. Students will need to catch up later. Therefore, the best thing teachers can do for their students is not to cram as much in as possible now. Instead, they can focus on helping students become better independent learners. Homework should be an opportunity for students to plan, monitor, reflect, and adjust their own learning. It should be an opportunity for students to practice time management, to think about how they can get help when they need it, and to learn what works in their individual lives. Teachers can figure out where their students are as self-regulating learners and help them to take the next step to level up this skill.

\section{(3) Effort and motivation arise from "expectancy" and "value."}

Since teachers are not present to watch over students outside of school, giving homework only matters if students will be motivated to put effort into it. What theory tells us is that a typical teacher's "bag of tricks" isn't that effective. Giving rewards, grades, punishments, threats, and the like related to completing homework should not be the focus, especially during this pandemic. Instead, teachers can focus on two questions:

1. Do students value their homework assignments; do they believe that doing the homework helps them learn? (Hint: usually they will value homework when it clearly connects to some next step in a learning process, not because of what they felt as they were doing homework. And homework is never that fun compared to the alternatives, so don't set overly high expectations.) Homework should have learning value and connect to various forms of engagement, but should not just be entertainment value.

2. Do students expect they can make progress on their own? If it's too hard, or not hard enough, they will waste their precious learning time. Students will apply effort to homework when they believe doing so will help them to learn. Teachers can talk to their students about how learning works and ask them what helps them to learn. Building students' theories of themselves as learners can help them understand why and how doing homework can help them grow. 


\section{(4) Incorporate spaced, interleaved practice.}

As noted above, homework is better when it's not all about same-day content, but helps students prepare for future lessons. Research also strongly supports spacing out homework over time. When students study or do homework on a topic spread over days and weeks, they learn more and remember it better (Wiseheart et al., 2019). This means teachers can include some math problems on fractions (a past topic) after they have moved onto decimals. It means returning to the meaning of important concepts like cause and effect again and again. It means asking students to process a chapter they read in several steps, on different days, not all at once. In addition, it means bringing together concepts from past, present, and future, in order to help students independently realize the connections between those concepts and how those connections relate to the larger picture of what is being learned. Interleaving, or mixing questions from previous topics with questions about recent topics, is another effective strategy. Research supports interleaving briefer, easier problems with longer, more challenging ones; this results in students learning more.

\section{A Partnership with Those Supporting Learning at Home}

By this point in the pandemic, teachers are no doubt realizing, more than ever, how important it is to partner with parents, guardians, and other adults supporting learning at home. The research on homework tells us that parents and guardians can have a mixed impact on homework. If parents and guardians focus on compliance (e.g., "Do your homework! Now!"), some researchers report negative impacts on student learning (Fernández-Alonso et al., 2015). Conversely, when parents and guardians focus on supporting student effort and helping with the learning process, the effects can be very good (Vazquez et al., 2020). Studies are beginning to show that even simple text messages to parents to remind them when and how to help can be very effective (Bergman \& Chan, 2019).

Teachers can start including parents, guardians, and other adults supporting learning at home in sharing stories about how learning happens. This could be, for example, giving those available for support at home clear roles in the learning process and nudging them away from focusing on homework completion or the exact timing of when homework gets done.

How can parents and guardians support their students to become self-regulating learners? They can help their students plan, monitor, reflect on, and adapt their learning process. Parents and guardians are teachers' biggest allies in building self-regulating learners, and increasing student independence around learning is the best thing teachers and parents can do to enable students to be resilient learners during and after this pandemic. 


\section{Putting the Research to Work}

In the midst of the COVID-19 pandemic, educators have been forced to rethink and redesign learning to fit into hybrid or remote models. Students are being increasingly assigned more independent work than when learning was face-to-face. Although no specific research currently exists on best pedagogical practices during a pandemic, we do have the opportunity to leverage the existing research on homework, and the technology that supports effective homework. By incorporating the principles and design ideas laid out above, teachers can support their students, at a distance, to grow into engaged, self-directed learners. 


\section{References}

Bergman, P., \& Chan, E. W. (2019). Leveraging parents through low-cost technology: The impact of high-frequency information on student achievement. Journal of Human Resources, https://doi.org/10.3368/jhr.56.1.1118-9837R1.

Cooper, H., Steenbergen-Hu, S., \& Dent, A. L. (2012). Homework. In K. R. Harris, S. Graham, T. Urdan, A. G. Bus, S. Major, \& H. L. Swanson (Eds.), APA handbooks in psychology. APA educational psychology handbook, Vol. 3. Application to learning and teaching (p. 475495). American Psychological Association. https://doi.org/10.1037/13275-019

Dettmers, S., Trautwein, U., Lüdtke, O., Kunter, M., \& Baumert, J. (2010). Homework works if homework quality is high: using multilevel modeling to predict the development of achievement in mathematics. Journal of Educational Psychology, 102(2), 467. https://doi.org/10.1037/a0018453

Elawar, M. C., \& Corno, L. (1985). A factorial experiment in teachers' written feedback on student homework: Changing teacher behavior a little rather than a lot. Journal of Educational Psychology, 77(2), 162. https://doi.org/10.1037/0022-0663.77.2.162

Fernández-Alonso, R., Suárez-Álvarez, J., \& Muñiz, J. (2015). Adolescents' homework performance in mathematics and science: personal factors and teaching practices. Journal of Educational Psychology, 107(4), 1075. https://doi.org/10.1037/edu0000032

Gray, L., \& Lewis, L. (2020). Teachers' Use of Technology for School and Homework Assignments: 2018-19. First Look. NCES 2020-048. National Center for Education Statistics.

Mendicino, M., Razzaq, L., \& Heffernan, N. T. (2009). A comparison of traditional homework to computer-supported homework. Journal of Research on Technology in Education, 41(3), 331-359. https://doi.org/10.1080/15391523.2009.10782534

Roschelle, J., Feng, M., Murphy, R. \& Mason, C.A. (2016). Online mathematics homework increases student achievement. AERA Open, 2(4), 1-12. https://doi.org/0.1177/2332858416673968

Vazquez, S. R., Ermeling, B. A., \& Ramirez, G. (2020). Parental Beliefs on the Efficacy of Productive Struggle and Their Relation to Homework-Helping Behavior. Journal for Research in Mathematics Education, 51(2), 179-203. https://doi.org/10.5951/jresematheduc-2020-0019 
Wiseheart, M., Küpper-Tetzel, C. E., Weston, T., Kim, A. S. N., Kapler, I. V., \& Foot-Seymour, V. (2019). Enhancing the quality of student learning using distributed practice. In J. Dunlosky \& K. A. Rawson (Eds.), The Cambridge Handbook of Cognition and Education (p. 550-583). Cambridge University Press. https://doi.org/10.1017/9781108235631.023 